\title{
Conditioned freezing in the rat as a function of shock intensity and CS modality
}

\author{
RONALD A. SIGMUNDI, MARK E. BOUTON, and ROBERT C. BOLLES \\ University of Washington, Seattle, Washington 98195
}

\begin{abstract}
The present data confirm previous reports that freezing in the rat is a useful index of aversive conditioning. Forward conditioning produced reliable CS-evoked freezing in comparison with pseudoconditioning controls. When a white noise was the CS, conditioned freezing increased with shock intensity; when a localized light was the CS, freezing did not vary with shock intensity.
\end{abstract}

The conditioned suppression procedure (Estes \& Skinner, 1941) assesses the strength of aversive conditioning by measuring the ability of a CS that signals shock to suppress appetitive behavior. In the rat, a substantial amount of freezing accompanies this suppression (e.g., Hunt, Jernberg, \& Brady, 1952). The loss of appetitive behavior and the increase in freezing, a defensive behavior, tend to be strongly correlated (Bouton \& Bolles, Note 1). This suggests that the amount of freezing evoked by a CS can serve as an alternative to the more customary conditioned suppression index of conditioning. Although the freezing index has been used occasionally (e.g., Bouton \& Bolles, 1979; Fanselow $\&$ Bolles, 1979b), justification for more widespread use requires further validation against experimental parameters that are known to affect the strength of conditioning.

Data from the appetitive suppression procedure indicate that the strength of fear conditioning increases with shock intensity (Annau \& Kamin, 1961; Kamin \& Brimer, 1963). If freezing is to be a meaningful index of aversive conditioning, then freezing should increase with shock intensity in the same manner. This relationship has been demonstrated for freezing evoked by contextual cues (Blanchard \& Blanchard, 1969; Fanselow \& Bolles, 1979a), but the corresponding relationship has not been demonstrated for discrete CSs. The present study investigated the relationship between shock intensity and CS-evoked freezing.

\section{METHOD}

\section{Subjects}

Forty eight male rats of Wistar descent, about 100 days old, were used. They were housed individually and maintained on a natural light-dark cycle with free access to food and water.

\section{Apparatus}

Two black plywood conditioning boxes $(35 \times 30 \times 30 \mathrm{~cm})$ with clear acrylic front doors were located in sound attenuation chambers. Scrambled shock (Grason-Stadler 700 shock source) could be delivered through the grid floors, which were made of $9-\mathrm{mm}$ stainless steel rods spaced $1.8 \mathrm{~cm}$ center to center. Each box was continuously lighted by a $7.5-\mathrm{W}$ red houselight attached to the ceiling. The onset of one $15-\mathrm{W}$ incandescent light, also attached to the center of each ceiling, served as a CS. The second CS was a white noise $(62 \mathrm{~dB}$ over a $60 \mathrm{~dB}$ background re $20 \mu \mathrm{N} / \mathrm{m}^{2}$ ), delivered through a speaker located in the rear portion of the ceiling. One of the two boxes was arbitrarily chosen as the test chamber for the second phase of the experiment.

\section{Procedure}

The study was run during the day. The animals were randomly assigned to a 2 by 2 by 3 factorial design $(n=4)$ with two CS modalities in testing (light and white noise), two conditioning procedures (forward conditioning and pseudoconditioning), and three shock intensities $(.5,1.0$, and $2.0 \mathrm{~mA})$. All animals were given one 60 -min conditioning session in which the CS was presented 15 times on a variable-time (VT) 3 -min schedule. The CS was $60 \mathrm{sec}$ in duration, and it terminated with a .5 -sec shock. The white noise served as a CS for one-half of the animals; the remaining animals received the light as the CS. The next day each animal had a $60-\mathrm{min}$ recovery session in the conditioning box, with no events programmed. On each of the next 4 days, each animal had a 6 -min extinction session in the test chamber with the CS alone. It was presented during Minute 4. One-half of the animals in each conditioning group received the CS that had been paired with shock, and the remaining animals received the opposite, novel CS.

During the test sessions, behavior was sampled every $5 \mathrm{sec}$ for a 60 -sec period immediately prior to the CS and for the $60-\mathrm{sec}$ duration of the CS by an observer that was "blind" to the conditioning treatments. For one-half of the animals in each group, a second, "blind" observer independently sampled behavior on the first test trial. Throughout testing, freezing was defined as the absence of movement except for breathing; all other nonfreezing behaviors were designated "activity." In order to present the data in the familiar suppression ratio form, activity-suppression ratios were calculated on each trial for each rat by dividing the number of nonfreezing samples observed during the CS by the total number of nonfreezing samples that were observed during the CS and pre-CS periods. An activitysuppression ratio of 0 indicates freezing throughout the CS; a ratio of .5 indicates no difference in freezing (or activity) between the CS and pre-CS periods.

\section{RESULTS}

Pre-CS freezing scores were collapsed across the four test trials and analyzed with a 2 by 2 by 3 analysis of variance. CS modality in testing produced the only reliable effect on pre-CS freezing $[F(1,16)=4.62$, 


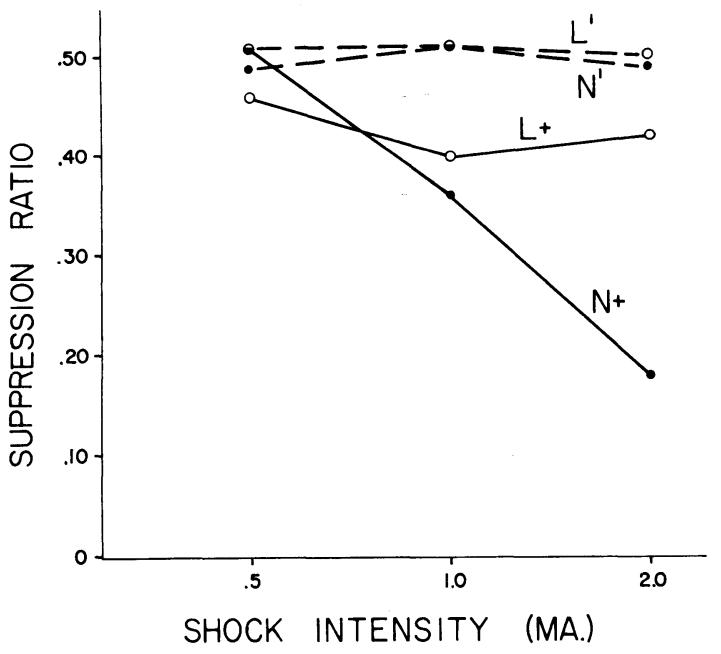

Figure 1. Group mean activity-suppression ratios based on a 60 -sec pre-CS period and a 60 -sec CS. Groups were tested with either a forward conditioned white noise $(\mathrm{N}+)$, a forward conditioned light $(\mathrm{L}+)$, a novel white noise $\left(\mathrm{N}^{\prime}\right)$, or a novel light $\left(\mathrm{L}^{\prime}\right)$. Each group mean has been collapsed across four test trials.

$\mathrm{p}<.05$ ] ; less freezing occurred in the pre-CS period in animals tested with the light (mean proportion $=.07$ ) than in animals tested with the noise (mean proportion = .10). This effect was small enough that it did not bias the activity-suppression ratios. Any bias that occurred should have been toward larger suppression ratios for the noise than for the light.

Suppression ratios based on the observations of the independent observers were highly correlated $[\mathrm{r}(23)=$ $.98, \mathrm{p}<.01]$. The suppression ratios were collapsed across the four test trials and analyzed with a 2 by 2 by 3 analysis of variance. All main effects and interactions were reliable $(\mathrm{Fs}>4.54$, ps $<.05)$. These data are shown in Figure 1.

The data indicate that, in comparison with a novel $\mathrm{CS}$, forward conditioning produced reliable freezing that is expressed by the activity-suppression ratio. Second, suppression of activity increased with US intensity. This effect was specific to the forward conditioning procedure and to the white-noise CS. Finally, although the forward conditioned light suppressed activity in comparison with a novel light control $[\mathrm{F}(1,18)=5.66$, $p<.05$ ], it produced less suppression of activity than the white noise, and the suppression was not responsive to the manipulation of US intensity.

\section{DISCUSSION}

These results support the use of freezing as an index of aversive conditioning. The time-sampling method proved again to be a reliable way to measure freezing (see Bouton \& Bolles, 1979; Fanselow, 1980; Bouton \& Bolles, Note 1). CS-evoked freezing increased with US intensity, and the effect was specific to forward pairings of the CS and shock. Similar results would be expected from alternative measures of conditioning, such as the conditioned suppression of appetitive behavior (e.g., Annau \& Kamin, 1961), and these results would be predicted from several models of conditioning (e.g., Mackintosh, 1975b; Rescorla \& Wagner, 1972; Wagner, 1978).

Freezing has been characterized as respondent behavior (Bolles \& Riley, 1973) under the control of discrete stimuli (Bindra \& Palfai, 1967; Bouton \& Bolles, 1979; Collier, 1977; Davitz, Mason, Mowrer, \& Viek, 1957; Fanselow, 1980; Fanselow \& Bolles, 1979b) and static, apparatus cues (Blanchard \& Blanchard, 1969; Bolles \& Collier, 1976) that predict shock. It is one component of a system of defense reactions used by the rat in dangerous situations (Bolles, 1975, 1978; Bolles \& Fanselow, in press). Several studies demonstrate that the selection of a specific behavior from within this system depends on appropriate stimulus support for the behavior from the environment (Blanchard \& Blanchard, 1970a, 1970b; Blanchard, Fukunaga, \& Blanchard, 1976a, 1976b; Bolles \& Collier, 1976; Grossen \& Kelley, 1972; Pinel \& Treit, 1979). Although these studies indicate that the rat may be capable of a variety of defensive behaviors, aversive conditioning studies frequently take place in a small, barren chamber that provides little stimulus support for much of the animal's defense repertory. Aversive conditioning in this type of environment typically produces a tendency to freeze, and this tendency is correlated with the conditioned suppression of appetitive baselines (Bouton \& Bolles, Note 1). We may suppose that aversive conditioning results in the formation of a central mediator that selectively facilitates defense reactions appropriate to the dangerous situation (Bolles, 1975; Bolles \& Fanselow, in press). The present data suggest that the degree of facilitation by the mediator increases with shock intensity, resulting in a greater incidence of defensive freezing.

These considerations help to validate freezing as an index of aversive conditioning by showing (1) that freezing is responsive to the manipulation of shock intensity in a manner consistent with our knowledge of fear conditioning, (2) that freezing is controlled by stimuli that predict shock in a manner consistent with views of defensive behavior, (3) that freezing is correlated with other accepted indices of aversive conditioning, and (4) that freezing can be reliably measured with time-sampling procedures.

Topographical indices of conditioning, such as the freezing index, focus on the form of behavior and derive their value by emphasizing the problem of response selection in conditioning. At one time, the solution to the response-selection problem seemed to depend on the determination of whether S-R contiguity or reinforcement was the basis of conditioning; however, the problem has been compounded with the conviction that the stimulus and response are mediated by central events (see Rescorla \& Solomon, 1967). Now, in addition to laws of association that describe the acquisition of the mediator, we need to specify rules that tie the mediator to overt behavior. The conditioned suppression procedure neglects this problem by focusing attention on the elimination of appetitive behavior, rather than on the form or topography of defensive behavior. Topographical indices of conditioning shift the focus back toward the animal's behavior.

On the basis of the freezing index, one might conclude that, because the light evoked little freezing, it did not condition well. Although some have argued that a light is a poor signal for shock (e.g., Jacobs \& LoLordo, 1977), there are data to the contrary (Kamin, 1969; Mackintosh, 1975a; Welker \& Wheatley, 1977), and there is another possibility. Comparable levels of fear may have been conditioned to the light and noise, and each CS may have produced a different form of defensive behavior in a manner analogous to that reported by Holland (1977) for appetitive behavior. Just as different stimulus characteristics of the environment can support different defense reactions, CSs may contribute their own behavioral support stimuli to dictate the form of a versively motivated behavior. 


\section{REFERENCE NOTE}

1. Bouton, M. E., \& Bolles, R. C. Conditioned fear assessed by freezing and by the suppression of three different baselines. Manuscript submitted for publication, 1979.

\section{REFERENCES}

Annau, Z., \& Kamin, L. J. The conditioned emotional response as a function of intensity of the US. Journal of Comparative and Physiological Psychology, 1961, 54, 428-432.

Bindra, D., \& PalfaI, T. Nature of positive and negative motivational effects on general activity. Journal of Comparative and Physiological Psychology, 1967, 63, 288-297.

Blanchard, R. J., \& Blanchard, D. C. Crouching as an index of fear. Journal of Comparative and Physiological Psychology, 1969, 67, 370-375.

Blanchard, R. J., \& BlanchaRd, D. C. Dual mechanisms in passive avoidance: I. Psychonomic Science, 1970, 19, 1-2. (a)

Blanchard, R. J., \& Blanchard, D. C. Dual mechanisms in passive avoidance: II. Psychonomic Science, 1970, 19, 3-5. (b)

Blanchard, R. J., Fukunaga, K. K., \& Blanchard, D. C. Environmental control of defensive reactions to a cat. Bulletin of the Psychonomic Society, 1976, 8, 179-181 . (a)

Blanchard, R. J., Fukunaga, K. K., \& Blanchard, D. C. Environmental control of defensive reactions to footshock. Bulletin of the Psychonomic Society, 1976, 8, 129-130. (b)

Bolles, R. C. Theory of motivation (2nd ed.). New York: Harper \& Row, 1975.

Bolles, R. C. The role of stimulus learning in defensive behavior. In S. H. Hulse, H. Fowler, \& W. K. Honig (Eds.), Cognitive processes in animal behavior. Hillsdale, N.J: Erlbaum, 1978.

Bolles, R. C., \& Collier, A. C. Effect of predictive cues on freezing in rats. Animal Learning \& Behavior, 1976, 4, 6-8.

Bolles, R. C., \& Fanselow, M. S. A perceptual-defensiverecuperative model of fear and pain. Behavioral and Brain Sciences, in press.

Bolles, R. C., \& RILEY, A. L. Freezing as an avoidance response: Another look at the operant-respondent distinction. Learning and Motivation, 1973, 4, 268-275.

Bouton, M. E., \& Bolles, R. C. Contextual control of the extinction of conditioned fear. Learning and Motivation, 1979, 10, 445-466.

Collier, A. C. Preference for shock signals as a function of the temporal accuracy of the signals. Learning and Motivation, $1977,8,159-170$.

Davitz, J. R., Mason, D. J., Mowrer, O. H., \& Viek, P. Conditioning of fear: A function of the delay of reinforcement. American Journal of Psychology, 1957, 70, 69-74.

Estes, W. K., \& Skinner, B. F. Some quantitative properties of anxiety. Journal of Experimental Psychology, 1941, 29, 390-400.

FANSELOW, M. S. Signalled shock-free periods and preference for signalled shock. Journal of Experimental Psychology: Animal Behavior Processes, 1980, 6, 65-80.
Fanselow, M. S., \& Bolles, R. C. Naloxone and shock-elicited freezing in the rat. Journal of Comparative and Physiological Psychology, 1979, 93, 736-744. (a)

Fanselow, M. S., \& Bolles, R. C. Triggering of the endorphin analgesic reaction by a cue previously associated with shock: Reversal by naloxone. Bulletin of the Psychonomic Society, 1979, 14, 88-90. (b)

Grossen, N. E., \& Kelley, M. J. Species specific behavior and acquisition of avoidance behavior in rats. Journal of Comparative and Physiological Psychology, 1972, 81, 307-310.

Holland, P. C. Conditioned stimulus as a determinant of the form of the Pavlovian conditioned response. Journal of Experimental Psychology: Animal Behavior Processes, 1977, 3, 77-104.

Hunt, H. F., Jernberg, P., \& Brady, J. V. The effect of electroconvulsive shock on a conditioned emotional response: The effect of post-ECS extinction on the reappearance of the response. Journal of Comparative and Physiological Psychology, 1952, 46, 589-599.

JACOBs, W. J., \& LoLordo, V. M. The sensory basis of avoidance responding in the rat: Relative dominance of auditory or visual warning signals and safety signals. Learning and Motivation, 1977, 8, 448-466.

KAMIN, L. J. Predictability, surprise, attention, and conditioning. In B. A. Campbell \& R. M. Church (Eds.), Punishment and aversive behavior. New York: Appleton-Century-Crofts, 1969.

Kamin, L. J., \& Brimer, C. J. The effects of intensity of conditioned and unconditioned stimuli on a conditioned emotional response. Canadian Journal of Psychology, 1963, 17, 194-198.

Mackintosh, N. J. Blocking of conditioned suppression: Role of the first compound trial. Journal of Experimental Psychology: Animal Behavior Processes, 1975, 1, 335-345. (a)

Mackintosh, N. J. A theory of attention: Variations in the associability of stimuli with reinforcement. Psychological Review, 1975, 82, 276-298. (b)

Pinel, J. P. J., \& Treit, D. Conditioned defensive burying in rats: Availability of burying material. Animal Learning \& Behavior, 1979, 7, 392-396.

Rescorla, R. A., \& Solomon, R. L. Two-process learning theory: Relationships between Pavlovian conditioning and instrumental learning. Psychological Review, 1967, 74, 151-182.

Rescorla, R. A., \& Wagner, A. R. A theory of Pavlovian conditioning: Variations in the effectiveness of reinforcement and nonreinforcement. In A. H. Black \& W. F. Prokasy (Eds.), Classical conditioning II: Current research and theory. New York: Appleton-Century-Crofts, 1972.

WAGNER, A. R. Expectancies and the priming of STM. In S. H. Hulse, H. Fowler, \& W. K. Honig (Eds.), Cognitive processes in animal behavior. Hillsdale, N.J: Erlbaum, 1978.

Welker, R. L., \& WheAtLey, K. L. Differential acquisition of conditioned suppression in rats with increased and decreased luminance levels as CSs. Learning and Motivation, 1977, 8, 247-262.

(Received for publication February 8, 1980.) 